\title{
Conhecendo o Processo de Inclusão Escolar em Porto Velho - RO
}

\author{
Iracema Neno Cecilio Tada ${ }^{1}$ \\ Vanessa Aparecida Alves de Lima \\ Tânia Gonçalves Melo \\ Dagmara Yuki Vieira Tomotani Correio \\ Universidade Federal de Rondônia
}

\begin{abstract}
RESUMO - A pesquisa objetivou realizar levantamento estatístico sobre o número de alunos com deficiência matriculados, idade, tipo de deficiência mais frequente, estrutura física das escolas e modalidade de ensino oferecida em 22 escolas da rede pública e privada de Porto Velho/RO. Para coleta de dados utilizou-se diário de campo e análise documental. Há 104 alunos com deficiência matriculados no ensino comum, com faixa etária de 5 a 25 anos, com defasagem idade/série, sendo os diagnósticos mais comuns de deficiência intelectual e hiperatividade. Verificou-se que a matrícula dos alunos surdos em salas regulares tem baixa incidência. Os dados indicam que pais e escolas buscam matricular a pessoa com deficiência nas escolas regulares.
\end{abstract}

Palavras-chave: inclusão escolar; aluno com deficiência; acessibilidade.

\section{Knowing the School Inclusion Process in Porto Velho - RO}

\begin{abstract}
The purpose of this study was to investigate the number of enrolled students with learning deficits, their ages, and the most common types of deficits in 22 regular schools (both private and public) in Porto Velho (Rondônia). Field diaries and documental analysis were used as data sources. A total of 104 students, ranging in age from 5 to 25 years, with deficits were enrolled in the regular educational system, all lagging behind in school. The most common diagnosed problems amongst these students were intellectual deficit and hyperactivity. The enrollment of deaf students in regular classrooms appeared to have a low incidence. The results showed that parents and schools seek to enroll students with deficits in regular schools.
\end{abstract}

Keywords: school inclusion; students with deficiencies; accessibility.

Em nossa convivência no cotidiano escolar, trabalhando com professores e gestores, escutamos muitas queixas, principalmente dos professores, de que se sentem despreparados para lidar com o processo de inclusão. Da mesma forma, as pesquisas que discutem este processo têm relatado as dificuldades encontradas pelas escolas em escolarizar o aluno com deficiência em decorrência de um longo processo histórico-cultural de exclusão (Abenhaim, 2005; Emílio, 2004; Prieto, 2005; Tada, 2005).

Pode-se dizer que a principal dificuldade dos profissionais em lidar com o aluno com deficiência consiste não só no aspecto funcional, mas também no estigma que carregam e para que aconteça uma verdadeira educação inclusiva, há necessidade de modificações na formação destes profissionais, mudança de atitudes e valores em relação ao aluno com deficiência (Amaral, 2002).

Algumas escolas do ensino regular têm desenvolvido ações excludentes desde o processo de matrícula do aluno com deficiência, como pode ser observado no relato de Lurdinha (Tunes \& Piantino, 2001) sobre as exigências feitas por uma escola do Distrito Federal ao tentar matricular o seu filho com síndrome de Down que atingira a idade escolar. A diretora só matricularia se a mãe trouxesse três laudos: um médico, para conhecer as reais condições de saúde da criança;

1 Endereço para correspondência: Iracema Tada. MAPSI - Universidade Federal de Rondônia. BR 364, Km 9,5 Zonal Rural. Porto Velho, RO. CEP:76808-695.E-mail: iracematada@ig.com.br outro psicológico, para verificar se o menino tinha condições emocionais para conviver com crianças sem deficiência e, por último, o neurológico. Além deste constrangimento, Lurdinha precisaria pagar por uma auxiliar para ajudar a professora nas atividades de classe desenvolvidas com seu filho. Não concordando com tais exigências, matriculou-o em outra escola que solicitou a parceria com a família para que pudessem promover o seu processo de escolarização.

Em outras situações há descaso com as informações a respeito do diagnóstico da deficiência, tomando o senso comum e a observação leiga como dados suficientes. Como foi verificado por Tada (2005) ao conversar com gestores de uma escola particular de Porto Velho/RO sobre a matrícula de alunos com deficiência, informada que "tem aquele problema na cabeça, sabe qual é né? É cabeça pequena!” (p. 150) referindo-se a um aluno com microcefalia. A falta de informação sobre o diagnóstico da deficiência contribui para práticas pedagógicas inadequadas, tarefas descontextualizadas e diferentes de seus pares que colaboram para o isolamento do aluno na sala de aula (Emílio, 2004; Tada, 2005).

A exclusão também passa pela falta de preparo dos profissionais, seja na área da saúde ou da educação, ainda na formação inicial de conhecimentos sobre o desenvolvimento da pessoa com deficiência (Prieto, 2005; Pupo Filho, 1996), contribuindo para ações inadequadas frente à pessoa com deficiência. Buscando suprir a carência na formação do profissional da educação, principalmente do professor que poderá ter em sua sala de aula alunos com deficiência, 
o governo e órgãos não governamentais têm promovido a formação continuada "em projetos locais ou oficiais mais amplos" (Góes, 2004, p. 77). Apesar da importância desta ação, a qualidade tem variado muito, não alcançando o objetivo de capacitar o professor frente ao paradigma da inclusão escolar. Sem negar o mérito de esforços individuais e propostas localizadas, o fato é que o professor não tem tido experiências formativas suficientes ou suporte humano e material necessário para lidar com as novas demandas do trabalho pedagógico (Emílio, 2004; Tada, 2005).

Para Góes (2004), as ações para a inclusão não podem ser de responsabilidade apenas do professor de sala de aula, e devem, portanto, envolver todos os atores escolares, para que o projeto político pedagógico da escola seja de fato alterado para atender a especificidade dos alunos, seja na adequação arquitetônica e de recursos materiais ou na alteração curricular e metodológica de ensino.

Nesta perspectiva, acredita-se que os resultados desta pesquisa podem apresentar informações valiosas sobre o processo de inclusão na rede de ensino regular de Porto Velho/RO que têm alunos com deficiência matriculados. Busca compreender a maneira como a escola se organiza para receber estes alunos e tem como perguntas norteadoras: Que tipo de deficiência é a mais frequente no processo de inclusão? Quais as adaptações efetuadas para atender às necessidades escolares do aluno com deficiência? Quais os critérios utilizados para a matrícula deste aluno?

Desta forma, poderemos identificar possíveis entraves para uma melhor efetivação deste processo, buscando junto à comunidade escolar novas estratégias de intervenção e junto ao poder público a elaboração de políticas públicas que subsidiem o processo de inclusão.

\section{Método}

\section{Local do Estudo}

A pesquisa foi realizada em 22 escolas (10 estaduais, 8 municipais e 4 particulares) de Porto Velho/Rondônia, localizada no extremo norte do Estado, no período de 2006 a 2008, com população estimada em 380.974 habitantes (IBGE/2006), tendo 226.915 alunos matriculados na rede de ensino, sendo 129.172 nas escolas estaduais, 70.230 nas municipais e 27.513 nas particulares. De acordo com a Secretaria Estadual de Educação - SEDUC, Secretaria Municipal de Educação - SEMED e Conselho Estadual de Educação - CEE, o sistema educacional possui 67 escolas estaduais, 42 municipais e 58 particulares na área urbana.

Como procedimento para a coleta dos dados, foi realizado primeiramente contato telefônico com 82 escolas de fácil acesso à população, em virtude de sua localização (17 escolas estaduais, 40 municipais e 25 particulares), para saber se possuíam alunos com deficiência matriculados no ensino comum. Deste total, 49 informaram não ter alunos com deficiência matriculados (8 escolas estaduais, 24 municipais e 17 particulares), 11 informaram que não poderiam colaborar com a pesquisa e 22 aceitaram colaborar com a pesquisa.

\section{Participantes}

Participaram desta pesquisa os diretores de cada escola ou seu representante legal que concordaram com o Termo de Consentimento Livre e Esclarecido, agendando data e horário para o início da coleta dos dados. Nas escolas estaduais as informações foram coletadas com o diretor, ou com o psicólogo escolar, o orientador educacional ou a professora da sala de recursos, respeitando-se a orientação da direção escolar.

Em duas escolas municipais os gestores autorizaram o acesso aos documentos dos alunos com deficiência na secretaria. Em quatro escolas municipais não havia este registro, tendo a diretora ou a supervisora passado de sala em sala perguntando se haviam alunos com deficiência. Em uma das escolas uma professora anotou os resultados levantados em uma folha de rascunho entregando-a a uma das pesquisadoras. Em uma das escolas particulares, o diretor pedagógico se responsabilizou pela pesquisa cedendo os dados necessários. Nas outras, as informações foram coletadas com as coordenadoras pedagógicas.

\section{Instrumentos}

Para a coleta dos dados foram utilizados diário de campo e análise documental (Alves-Mazzotti \& Gewandsznajder, 2000). No diário de campo foram registradas se as escolas tinham adequação arquitetônica de acessibilidade para receber o aluno com deficiência - rampas, banheiros adaptados, carteiras adaptadas, materiais adaptados e a condição de uso. Registrou-se também se havia sala de recursos.

Como análise documental utilizou-se o levantamento de escolas com matrículas de alunos com deficiência da SEDUC, SEMED e CEE, dois relatórios sobre o desenvolvimento da rede de ensino do estado de Rondônia cedidos pelo Núcleo de Apoio a Educação Inclusiva (NAEDI) da Subgerência de Educação Especial da SEDUC e um levantamento estatístico dos alunos incluídos na rede municipal de ensino da Divisão de Ensino Especial (DIEES). Nas escolas os documentos foram o registro de matrícula dos alunos com deficiência a fim de identificar o tipo de deficiência, idade, série em que o aluno fora matriculado, o histórico escolar e assiduidade.

\section{Procedimento para Análise dos Dados}

Realizou-se um levantamento estatístico descritivo para mapear o número de alunos com deficiência matriculados, os tipos de deficiência, a série que este aluno cursa e as condições de acessibilidade. Para analisar os dados as informações obtidas a partir do levantamento estatístico foram agrupadas nas seguintes categorias: tipo de deficiência, alunos incluídos por série escolar e estrutura física das escolas.

\section{Resultados e Discussão}

A seguir são apresentados os resultados e a discussão de acordo com as categorias definidas nesta pesquisa. 
Tabela 1. Frequência Absoluta dos Tipos de Deficiência por Escola.

\begin{tabular}{|c|c|c|c|c|}
\hline & $\begin{array}{c}\text { Escolas Públicas } \\
\text { Estaduais }\end{array}$ & $\begin{array}{c}\text { Escolas Públicas } \\
\text { Municipais }\end{array}$ & $\begin{array}{c}\text { Escolas } \\
\text { Particulares }\end{array}$ & Total \\
\hline Deficiência Intelectual & 5 & 27 & 9 & 41 \\
\hline Deficiência Auditiva & 1 & 1 & 1 & 3 \\
\hline Deficiência Visual & 5 & 4 & 3 & 12 \\
\hline Deficiência Física & 6 & 4 & 3 & 13 \\
\hline Deficiência Múltipla & 3 & 3 & 1 & 7 \\
\hline $\begin{array}{l}\text { Transtorno Global } \\
\text { do Desenvolvimento }\end{array}$ & 0 & 2 & 1 & 3 \\
\hline Transtorno do Déficit de Atenção com Hiperatividade & 0 & 18 & 7 & 25 \\
\hline Total & 20 & 59 & 25 & 104 \\
\hline
\end{tabular}

Nas escolas pesquisadas havia 104 alunos com deficiência matriculados: 41 com o diagnóstico de deficiência intelectual; 13 com deficiência física, sendo 3 alunos em cadeira de rodas; 12 com deficiência visual; 3 com deficiência auditiva; 7 alunos com deficiência múltipla; 25 com transtorno de déficit de atenção com hiperatividade e 3 com transtorno global do desenvolvimento, como pode ser verificado na Tabela 1.

Identificar os tipos de deficiência dos alunos matriculados nas escolas de ensino regular possibilita que as instituições possam se organizar para que "todos os alunos tenham suas especificidades atendidas" como preconiza a Política $\mathrm{Na}$ cional de Educação Especial na Perspectiva da Educação Inclusiva (MEC/SEESP, 2008, p. 1). Os dados mostram que a inclusão escolar do aluno com deficiência intelectual é a mais frequente nas escolas investigadas representando 39,4\% do total da amostra.

O transtorno de déficit de atenção com hiperatividade é o segundo diagnóstico em termos de incidência nas escolas pesquisadas, totalizando 24\%. Embora este percentual não seja elevado em relação ao número total de alunos com deficiência matriculados, vale lembrar que Collares e Moysés (1996) têm questionado a alta incidência deste diagnóstico nas escolas brasileiras, enfatizando a necessidade de conhecer o cotidiano escolar onde o aluno é rotulado de hiperativo por alguns de seus professores por não ficar quieto na sala de aula. Questões sobre o número elevado de alunos por sala, a falta de ventilação e/ou iluminação adequada, a falta de tempo e espaço para o professor planejar a sua aula, entre outras podem contribuir para essa agitação e geralmente tendem a serem desconsideradas pela equipe responsável pelo diagnóstico.

A baixa incidência de alunos com deficiência auditiva (2,9\%) nas salas regulares, segundo a equipe técnica das escolas, ocorre em virtude dos alunos surdos optarem pelas classes especiais em função da própria deficiência com professor ouvinte ministrando aula em linguagem de sinais, sem sentirem-se constrangidos frente aos colegas ouvintes. Os dados das classes especiais não foram computados por não se configurarem como modalidade de inclusão.

Das escolas pesquisadas, $50 \%$ tinha em seus registros o diagnóstico da deficiência de seus alunos em termos de deficiência intelectual, auditiva, visual, física, múltipla, transtorno de déficit de atenção com hiperatividade e transtorno global do desenvolvimento, como discutido anteriormente, e cinquenta por cento não possuía esse registro. Havia apenas a crença de que o aluno apresentava algum tipo de deficiência. A falta do conhecimento sobre o diagnóstico da deficiência do aluno pode contribuir para um processo de inclusão questionável, por não ser possível planejar antecipadamente estratégias de intervenção adequadas para as necessidades dos alunos, conforme é determinado pelas Diretrizes Nacionais da Educação Especial do Ensino Básico (Brasil, 2001).

Tal situação foi observada por Tada (2005) em sua pesquisa com uma jovem com síndrome de Down. De acordo com a autora, os professores não tiveram informações sobre o diagnóstico da aluna e nem tempo para planejarem ações pedagógicas, sendo informados pela diretora que no dia seguinte receberiam uma "deficiente" e que deveriam agir com naturalidade. A maioria dos professores informou que devido ao "problema" da aluna não cobravam desta a realização das atividades como cobravam dos demais alunos, deixando inclusive que saísse da sala de aula quando desejasse. Quanto à aprovação de série, muitas vezes esta não se deu por mérito e sim por decisão do conselho de classe.

O número total de alunos por sala de aula variou entre 16 e 37 alunos, sendo a média de 27 alunos por turma com no máximo três alunos com deficiência inclusos, independente do tipo de deficiência e do número total de alunos por sala. Como pode ser verificado na Tabela 2, há 104 alunos com deficiência matriculados nas escolas pesquisadas. A rede municipal de ensino tem o maior número de alunos inclusos. Isto se deve ao fato do Ensino Fundamental ser de responsabilidade do município, como rege a Lei de Diretrizes e Bases da Educação Nacional (LDBEN 9394/96).

A incidência maior de matrícula de alunos com deficiência ocorreu no $2^{\circ}, 3^{\circ}$ e $4^{\circ}$ ano do Ensino Fundamental. Isto indica que os pais buscam matricular seus filhos com deficiência nas escolas regulares promovendo assim a convivência com crianças sem deficiência, ampliando as oportunidades interativas, como fez Lurdinha ao matricular seu filho com síndrome de Down na escola regular (Tunes \& Piantino, 2001).

A faixa etária dos alunos com deficiência matriculados no Ensino Fundamental foi de 5 a 25 anos, indicando grande disparidade. Havia alunos com 11, 16, 17 e 18 anos no $2^{\circ}$ ano, 14 anos no $3^{\circ}$ ano e 15 no $4^{\circ}$ ano. Considerando-se a defasagem idade/série Emílio (2004), em seu trabalho sobre inclusão escolar, discute que o agrupamento de alunos por série, considerando a equivalência nas necessidades peda- 
Tabela 2. Número de Alunos com Deficiência Matriculados por Série Escolar.

\begin{tabular}{|c|c|c|c|c|}
\hline & $\begin{array}{l}\text { Escolas Públicas } \\
\text { Estaduais }\end{array}$ & $\begin{array}{c}\text { Escolas Públicas } \\
\text { Municipais }\end{array}$ & $\begin{array}{c}\text { Escolas } \\
\text { Particulares }\end{array}$ & Total \\
\hline $1^{\circ}$ ano & 0 & 5 & 3 & 8 \\
\hline $2^{\circ}$ ano & 7 & 15 & 0 & 22 \\
\hline $3^{\circ}$ ano & 3 & 16 & 4 & 23 \\
\hline $4^{\circ}$ ano & 1 & 16 & 5 & 22 \\
\hline $5^{\circ}$ ano & 1 & 7 & 2 & 10 \\
\hline $6^{\circ}$ ano & 3 & 0 & 2 & 5 \\
\hline $7^{\circ}$ ano & 0 & 0 & 2 & 2 \\
\hline $8^{\circ}$ ano & 1 & 0 & 0 & 1 \\
\hline $9^{\circ}$ ano & 1 & 0 & 2 & 3 \\
\hline $1^{\circ}$ ano Ensino Médio & 4 & 0 & 4 & 8 \\
\hline Total & 21 & 59 & 24 & 104 \\
\hline
\end{tabular}

gógicas, seria o melhor caminho para facilitar o trabalho do professor. Entretanto para a autora, este não seria o caminho mais adequado do ponto de vista do aluno com deficiência, em função da grande diferença entre a sua idade e a dos colegas sem deficiência. Destaca ainda a necessidade da busca de outros critérios para que o processo seja de fato inclusivo. Há de levar-se em conta o número de alunos por sala, o número de alunos com deficiência por sala, as condições físicas e pedagógicas da escola, dentre outros fatores.

Nas visitas às 22 escolas pôde-se observar que a estrutura física nem sempre estava a favor dos alunos com deficiência, principalmente para aqueles que usam a cadeira de rodas bem como para os que são cegos ou possuem baixa visão. Considerando que dez escolas tinham muitos degraus e três apresentavam rampas e banheiros adaptados em precárias condições de conservação, o que pode trazer algum tipo de risco para estes alunos, ou limitar o espaço pelo qual eles possam circular, restringindo o seu contato interpessoal com outras pessoas.

Com relação à existência de sala de recursos nas escolas pesquisadas, somente algumas instituições públicas possuem estas salas, sendo seis escolas estaduais e três municipais. Em cinco escolas estaduais as salas de recursos não havia materiais como, por exemplo, objetos tácteis para avaliar e estimular a coordenação motora, recursos materiais para a ampliação de textos e imagens para os alunos com baixa visão, computadores adaptados para atender às necessidades dos alunos com deficiência múltipla, entre outros. Além desta situação os poucos recursos materiais disponíveis não eram adaptados para a faixa etária do aluno com deficiência. Apenas em uma escola havia materiais específicos para se trabalhar com alunos com deficiência visual (livros em braile, computadores com Dosvox, impressoras e máquina Perkins Braile).

Nas escolas municipais uma sala de recursos tinha livros em braile, nas outras duas apenas jogos pedagógicos, sendo que as salas costumeiramente são usadas como sala de leitura ou para aulas de reforço. Considerando que a sala de recursos é um espaço de atendimento pedagógico especializado, que tem como finalidade suplementar (no caso dos alunos com altas habilidades/superdotação) e complementar (para os de- mais alunos) o atendimento educacional realizado em classes comuns da rede regular de ensino por meio de equipamentos e recursos pedagógicos adequados às necessidades educacionais especiais dos alunos (MEC/SEESP, 2006, 2008), a situação das salas verificadas nesta pesquisa é preocupante, visto que a maioria não possui material adequado. Essa situação pode contribuir para que o aluno com deficiência não tenha suas necessidades educacionais atendidas.

Com relação às modalidades de ensino oferecidas aos alunos com deficiência, verificou-se que cinco escolas estaduais também atendem em classes especiais. Há quatro salas especiais para alunos com deficiência auditiva, totalizando 76 alunos matriculados e uma sala especial para cinco alunos com deficiência intelectual. A baixa quantidade de salas especiais constatado nesta pesquisa é um dado importante por demonstrar que as escolas estão efetivando a matrícula dos alunos com deficiência no ensino regular.

Como foi discutido anteriormente, a sala especial para os alunos com deficiência auditiva se deve ao fato dos próprios alunos optarem por esta modalidade de ensino em função de sua deficiência, como foi explicitado pelos diretores destas escolas. Embora seja uma opção dos alunos, é preciso considerar que permanecer nesta modalidade de ensino pode diminuir as oportunidades interativas com seus colegas sem deficiência como discutido por Machado (1994, 1997, 2000) e Padilha (2001).

\section{Considerações Finais}

Nesta pesquisa buscou-se analisar o número de alunos com deficiência matriculados em algumas escolas de Porto Velho, a defasagem idade/série, o tipo de deficiência mais frequente, a acessibilidade, a disponibilidade de recursos materiais nas salas de recursos, as modalidades de ensino oferecidas a estes alunos que historicamente eram encaminhados para instituições especiais, seja em regime de semi-internato ou internato, como bem retratado por Pessotti (1984) e Amaral (1995).

Embora o processo de inclusão escolar tenha vindo contribuir para que a sociedade valorize e respeite a diversidade 
humana, tendo em vista o longo processo de exclusão de alunos com deficiência, percebe-se que ainda há muito que caminhar. As categorias aqui discutidas revelam que as escolas, de maneira geral, não estão adaptadas para receber o aluno com deficiência, apresentando barreiras arquitetônicas que restringem o acesso deste aluno a determinados espaços escolares. As salas de recursos apresentam-se com poucos materiais, o que pode limitar o atendimento educacional aos alunos com deficiência. Há ainda a falta de conhecimento sobre o diagnóstico da deficiência de alguns alunos incluídos, e a defasagem idade/série.

Diante da constatação da grande defasagem idade/série alguns questionamentos são levantados: Será que os alunos com deficiência matriculados na Escola Regular vieram da classe ou escola especial ou eram multirrepetentes? Como os alunos sem deficiência e sem defasagem idade/série receberam seus colegas que possuem deficiência com idade avançada? Estas questões necessitam ser investigadas em novas pesquisas o que trará informações valiosas para a compreensão sobre o processo de inclusão escolar.

Pode-se dizer que pais e escolas, de forma geral, estão buscando se adequar ao processo de inclusão, como se verificou nesta pesquisa, o que não deixa de ser um salto qualitativo contra o preconceito, mas há muito mais para ser feito em prol do diálogo entre todas as pessoas envolvidas neste processo para que caminhos sejam construídos para o respeito à diversidade humana.

\section{Referências}

Abenhaim, E. (2005). Os caminhos da inclusão: breve histórico. In A. M. Machado, \& cols (Eds.), Educação inclusiva: direitos humanos na escola (pp. 39-54). São Paulo: Casa do Psicólogo.

Alves-Mazzotti, A. J., \& Gewandsznajder, F. (2000). O método nas ciências naturais e sociais: pesquisa quantitativa e qualitativa. São Paulo: Pioneira.

Amaral, L. A. (1995). Conhecendo a deficiência: em companhia de Hércules. São Paulo: Robe.

Amaral, L. A. (2002). Diferenças, estigma e preconceito: o desafio da inclusão. In M. K. Oliveira, D. T. R. Souza, \& T. C. Rego (Eds.), Psicologia, educação e as temáticas da vida contemporânea (pp. 233-248). São Paulo: Moderna.

Collares, C., \& Moysés, M. A. (1996). Preconceitos no cotidiano escolar: ensino e medicalização. São Paulo: Cortez; Campinas: UNICAMP.

Emílio, S. A. (2004). O cotidiano escolar pelo avesso: sobre laços, amarras e nós no processo de inclusão. Tese de Doutorado, Universidade de São Paulo, São Paulo.

Góes, M. C. R. (2004). Desafios da inclusão de alunos especiais: a escolarização do aprendiz e sua constituição como pessoa. In M. C. R. Góes, \& A. L. F. Laplane (Eds.), Políticas práticas de educação inclusiva (pp. 69-92). Campinas: Autores Associados.
IBGE (2006). Sistemas de Referência, Instituto Brasileiro de Geografia e Estatistica. Retrieved from http://www.ibge.gov. br/ibge/geografia/geodesico.

Lei n. 9.394 de 20 de dezembro de 1996 (1996). Estabelece as diretrizes e bases da educação nacional. Brasília: Ministério da Educação, Secretaria de Educação Básica. Retrieved from http://www.planalto.gov.br/ccivil_03/Leis/L9394.htm.

Machado, A. M. (1994). Crianças de classe especial: efeitos do encontro entre a saúde e educação. São Paulo: Casa do Psicólogo.

Machado, A. M. (1997). Relato de uma intervenção na escola pública. In A. M. Machado, \& M. P. R. Souza (Eds.), Psicologia escolar: em busca de novos rumos (pp. 93-106). São Paulo: Casa do Psicólogo.

Machado, A. M. (2000). Avaliação psicológica na escola: mudanças necessárias. In E. E. Tanamachi, M. Proença, \& M. Rocha (Eds.), Psicologia e educação: desafios teórico-práticos (pp. 143-167). São Paulo: Casa do Psicólogo.

Ministério da Educação (2006). Sala de reursos multifuncionais: espaço para atendimento educional especializado. Brasília: MEC/SEESP.

Ministério da Educação. (2008). Política Nacional de Educação Especial na Perspectiva da Educação Inclusiva. Brasília: MEC/SEESP.

Padilha, A. M. L. (2001). Possibilidades de histórias ao contrário: ou como desencaminhar o aluno da classe especial. São Paulo: Plexus.

Pessotti, I. (1984). Deficiência mental: da superstição à ciência. São Paulo: EDUSP.

Prieto, R. G. (2005). Inclusão escolar: algumas considerações sobre o conceito e suas implicações Psicologia e direitos humanos. In A. M. Machado, A. J. Veiga Neto, M. M. B. J. Neves, M. V. O. Silva, R. G. Prieto, W. Ranña, \& E. Abenhaim (Eds.), Psicologia e direitos humanos na escola: educação inclusiva, direitos humanos na escola (pp. 99-106). São Paulo: Casa do Psicólogo.

Pupo Filho, R. A. (1996). Sindrome de Down. E agora doutor? Um pediatra enfrenta sua desinformação ao ter uma filha com sindrome de Down. Rio de Janeiro: WVA.

Tada, I. N. C. (2005). Dialogando com Amanda: contribuições da teoria histórico-cultural na compreensão de uma jovem com sindrome de Down. Tese de Doutorado, Universidade de São Paulo, São Paulo.

Tunes, E., \& Piantino, L. D. (2001). Cadê a síndrome de Down que estava aqui? O gato comeu... O programa da Lurdinha. Campinas: Autores Associados.

Recebido em 25.08.2009

Primeira decisão editorial em 18.01.2011

Versão final em 16.03.2011

Aceito em 28.03.2011 